\title{
INFLUENCE OF CARDIAC SURGERY USING CARDIO-PULMONARY BYPASS ON METABOLIC REGULATION
}

\author{
Toshio ABE M.D.
}

$I^{\mathrm{N}}$ ORDER to investigate the influence of cardiac surgery using cordiopulmonary bypass on metabolic regulation, authors have studied mainly the influence of the cardio-pulmonary bypass using high blood sugar perfusate on the metabolic regulation of electrolytes, carbohydrates, lipids and amino acids in the present paper.

\section{The Subjects and Methods OF INVESTIGATION}

Cases in which studies were made of the metabolic regulation of electrolyte numbered 10; and, it was so arranged that the body surface area of the cases be not less than $1.2 \mathrm{~m}^{2}$, that the rotatory disc oxygenator be used and that cases be limited to those where the complete bypass has been performed for one hour or more.

The dilution rate of the perfusate for the heart-lung machine was set as $25 \%$, the perfusing flow as $2.0-2.21 / \mathrm{min} / \mathrm{m}^{2}$ and the lowest rectal temperature as $27^{\circ} \mathrm{C}, \mathrm{KCl} 20-25 \mathrm{mM}$ was added to perfusate for the heart-lung machine, and the potassium concentration was set as high as $11.4 \pm$ 1.6 (SD) $\mathrm{mEq} / 1$. Thereafter, care was taken not to add potassium during the extracorporeal circulation.

In cases where studies were made of the metabolic regulation of carbohydrates, lipids and amino acids the oxygenator included both the bubble type and the rotatory disc type. The dilution rate of perfusate for the heart-lung machine was set at $25 \%$, the perfusing flow at

\footnotetext{
Key Words:

Extracorporeal circulation

Metabolic regulation

Hypopotassemia

Lipolysis

Insulin
}

2.0-2.2 $1 / \mathrm{min} / \mathrm{m}^{2}$ and the lowest rectal temperature at $27-30^{\circ} \mathrm{C}$, and cases were divided into two groups by the concentration of glucose in perfusate, that is the normal blood sugar group and the high blood sugar group. The glucose concentration in perfusate of high sugar group was 1162 \pm 212 (SD) $\mathrm{mg} / \mathrm{dl}$.

As for the number of cases, Group 1: 6 cases of closed operation on heart, Group 2 (cardiac surgery using cardio-pulmonary bypass, normal blood sugar group): 10 cases, and Group 3 (cardiac surgery using cardio-pulmonary bypass, high blood sugar group): 12 cases.

On these cases, blood and urine were collected on a time-course basis, namely, before operation, on the day of operation and after operation; and then, measurements were taken of the following.

(1) Blood sugar (Hoffman method: Autoanalizer used), (2) Free fatty acids (Itaya-Ui method), (3) Free glycerol (Wieland method), (4) Glyceride glycerol (Wieland-Eggstein method), (5) $\alpha$-amino acids (Muting method), (6) Urea (Urease method), (7) Insulin (Double antibody method: Randle method), (8) Plasma electrolytes ( $\mathrm{Na}, \mathrm{K}, \mathrm{Cl}, \mathrm{Ca}, \mathrm{P}),(9)$ Amount of electrolytes excreted into urine $(\mathrm{Na}, \mathrm{K}, \mathrm{Cl}, \mathrm{Ca}, \mathrm{P})$, and (10) Amount of sugar excreted into urine.

\section{Results}

In 10 cases, blood sugar, blood insulin, prasma electrolytes and the amount of electrolytes excreted into urine were estimated by a timecourse, namely, after anesthesia, during extracorporeal circulation and two hours after the circulation. A part of the results was shown in Fig. 1 and 2.

The blood sugar increased markedly after initiation of the extracorporeal circulation due to sugar being produced by glycogenolysis and

(Received for publication: March 26, 1973)

The Ist Department of Surgery, University of Nagoya School of Medicine, 65 Tsurumai-cho, Showa-ku, Nagoya, Japan 


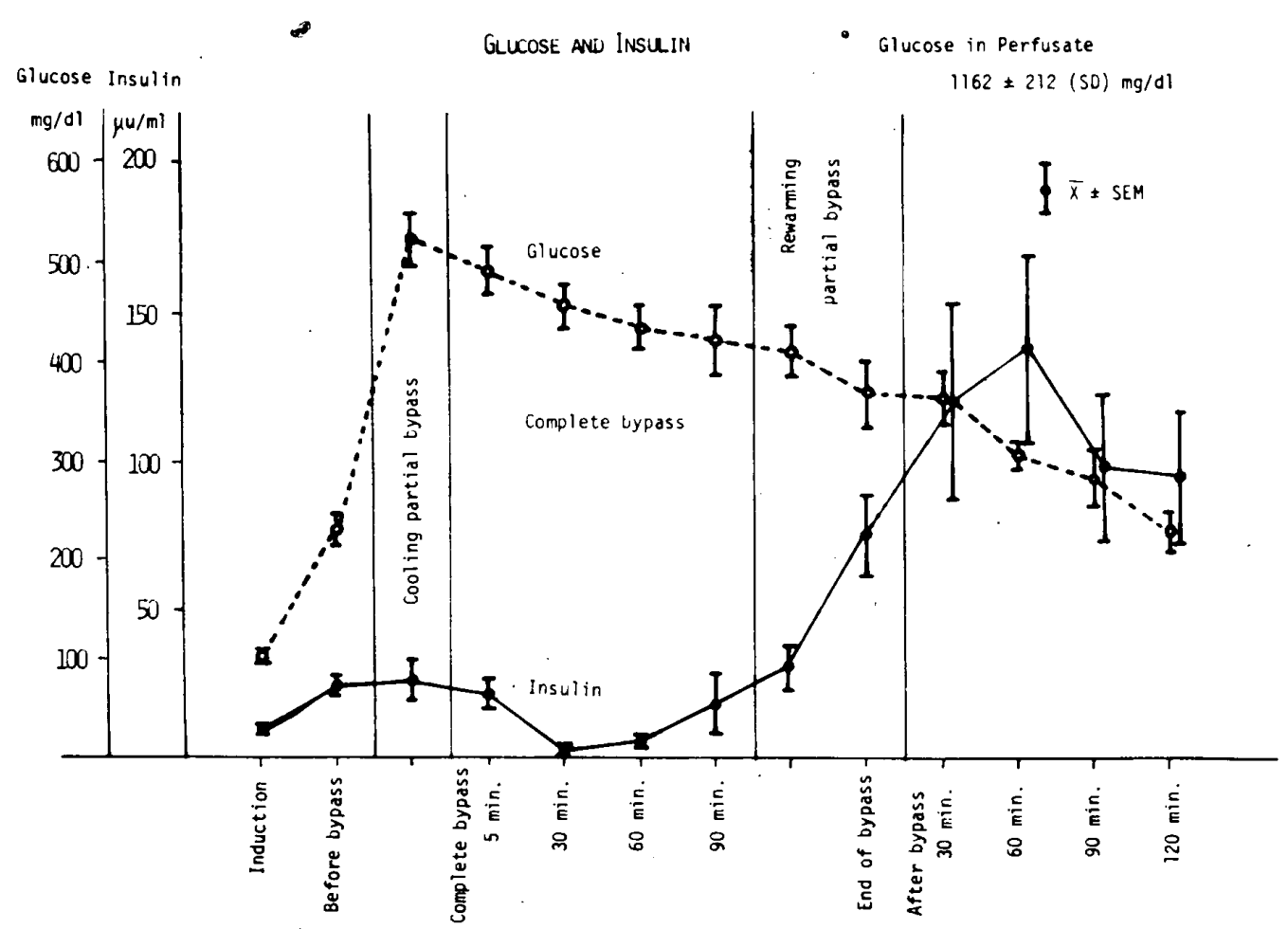

Fig.1. Glucose and Insulin.

PLASMA K

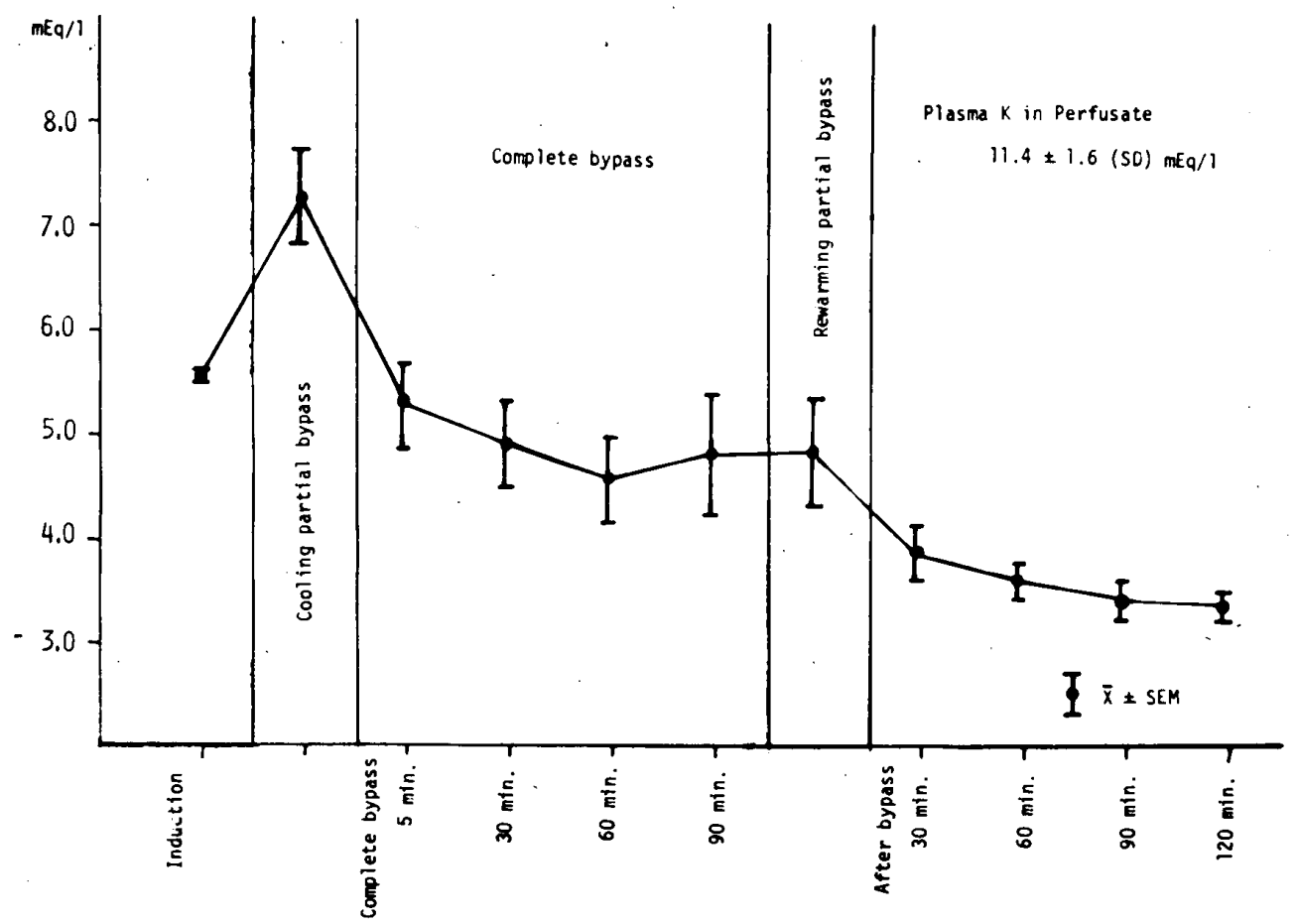

Fig.2. Plasma K.

glucose of the perfusate, and thereafter decreased gradually. In contrast, the blood insulin showed a slight rise in the early stage of the extracorporeal circulation, decreased during the extracorporeal circulation, started to increase from the time of rewarming partial bypass and increased markedly after termination of the extracorporeal circulation, while the blood sugar fell off.

When the perfuste for the heart-lung machine has been made of high potassium level as in these 


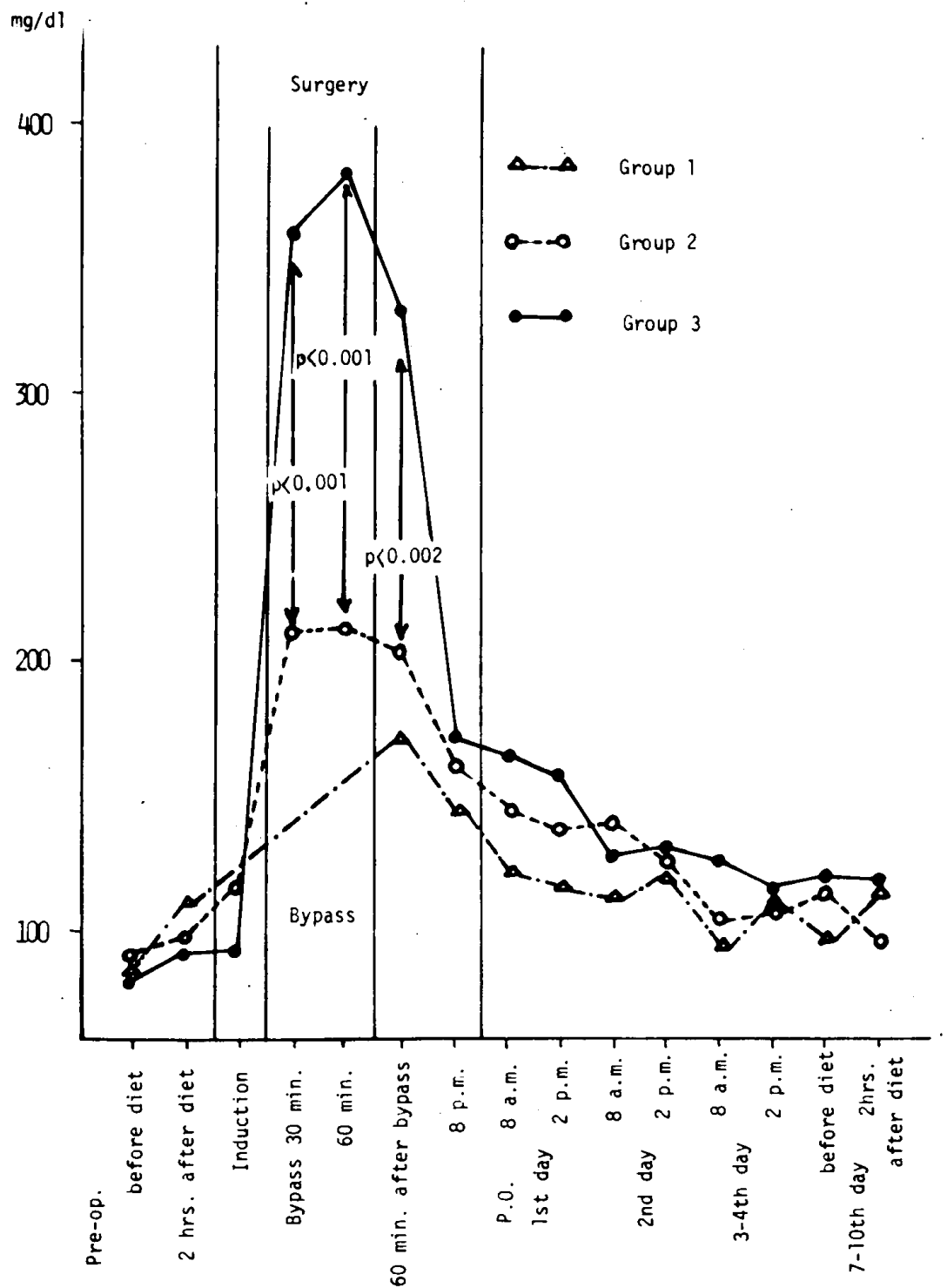

Fig.3. Glucose.

cases, the plasma potassium concentration shows a change as follows. Its concentration shows a first stage decrease by one hour after complete bypass and thereafter remains at the almost same level, and then occurs a second stage decrease after termination of the extracorporeal circulation, as shown in Fig. 2.

The mean value of blood sugar before operation, during operation and one week after operation was shown in Fig. 3, divided into the groups of the closed operation on heart (Group 1), the open heart operation by the normal blood sugar of the perfusate for heart-lung machine (Group 2 ), and by the high blood sugar perfusate (Group 3).In all groups, blood sugar rises on the day of operation and gets near the normal level on 2-3 days after operation. But there is a significant difference in blood sugar between the high blood sugar group and the normal blood sugar group of the perfusate during bypass and one hour after bypass, and this is considered to be due to the influence of the perfusate for the heart-lung machine. There is no statistical difference between the group of normal blood sugar perfusate and the group of closed heart operation.

Fluctuations in blood insulin one hour after bypass and blood insulin after operation were shown in Fig 4. The blood insulin one hour after bypass is high in the high blood sugar group, and it is inferred that the living body secretes more insulin to counteract that high blood sugar. The postoperative blood insulin is greatly varied; this seemed to be due to the amount of glucose in infusate, the use of agents affecting sympathetic nervous system ( $\beta$-stimulator and $\alpha$-blocker) and the use of adrenocortical hormon not having 


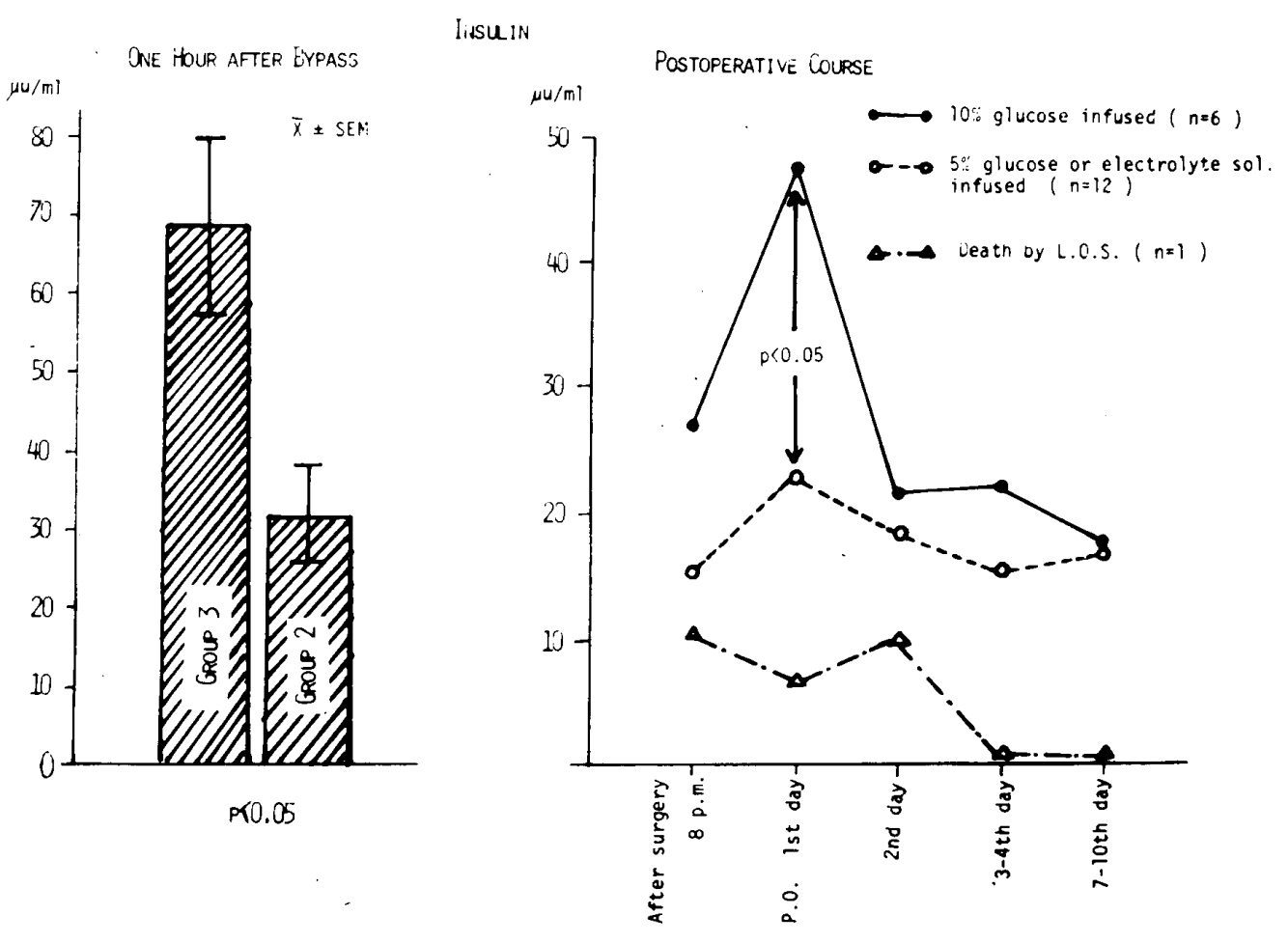

Fig.4. Insulin.

been made uniform after operation. When divided into six cases in which $10 \%$ glucose solution was used in the postoperative infusate and 12 cases in which $5 \%$ glucose or electroly te solution was used, the former showed a tendency for secretion of insulin to increase. In one patient who died of low output syndrome after corrective surgery of Fallot's tetralogy, the blood insulin was extremely low, and there seemed to be a viscious circle where the circulatory insufficiency resulted in a decrease of the insulin secretion and metabolic abnormality caused thereby deteriorated the function.

Free fatty acid rises slightly immediatly after anesthesia, and it increases with the start of the extracorporeal circulation and gets near the preoperative level one week after operation, as seen in Fig. 5. But there is a difference in fatty acid on the day of operation between the high blood sugar group and the normal blood sugar group of the perfusate for the heart-lung machine.

Free glycerol in blood, as shown in Fig. 6, shows a tendency almost similar to that of free fatty acids, thus corroborating that an increase in the amount of free fatty acids is due to acceleration of lipolysis. There is a tendency that free glycerol is normalized earlier after operation in the group of high blood sugar perfusate.

The fluctuation in blood $\alpha$-amino acids were shown in Fig. 7. The high blood sugar group of the perfusate tended to decrease $\alpha$-amino acids during bypass and immediately after operation. On the second day of operation and onward, $\alpha$-amino acid increased in all of the three groups.

Blood urea after operation also increased, showing a tendency almost similar to that of $\alpha$-amino acid, and it showed a tendency to be normalized earlier after operation in the high blood sugar group of the perfusate, as seen in Fig. 8.

\section{Discussion}

The inhibition of insulin secretion despite high blood sugar during the extracorporeal circulation is presumed to be attributable to an increase in the secretion of adrenalin due to the extracorporeal circulation, low body temperature and insufficient circulation of the viscera in the period of extracorporeal circulation.

As pathogenensis of hypopotassemis associated with cardiac surgery using cardiopulmonary bypass, mention has been made of dilution by the perfusate, and increase in excretion into urine and movement of potassium from extracellular fluid into cells. The influence of dilution can be excluded in this investigation, since the perfusate is made to have a high potassium concentration.

Accordingly, the amount of potassium excret- 


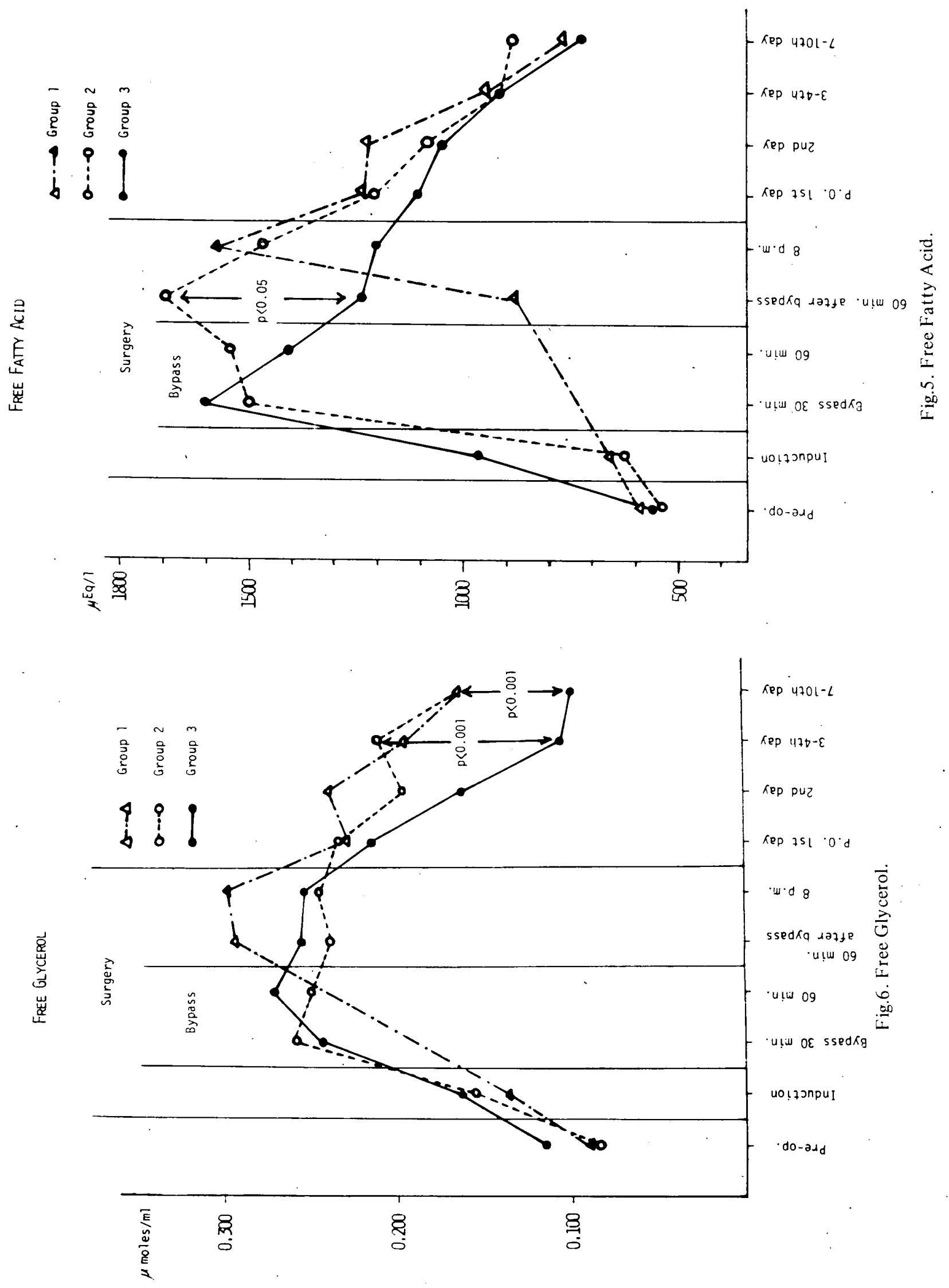



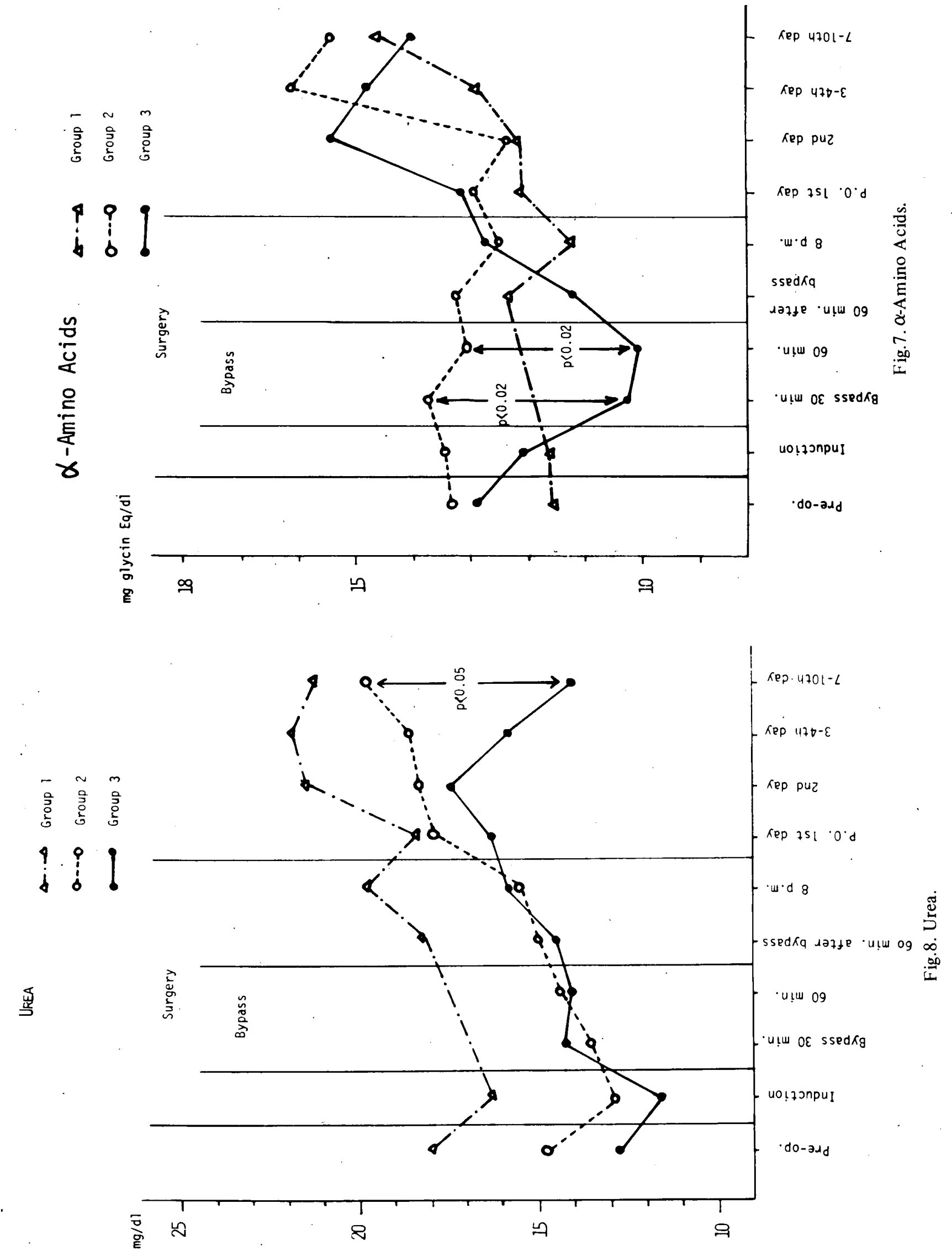

Japanese Circulation Journal Vol. 38, January 1974 

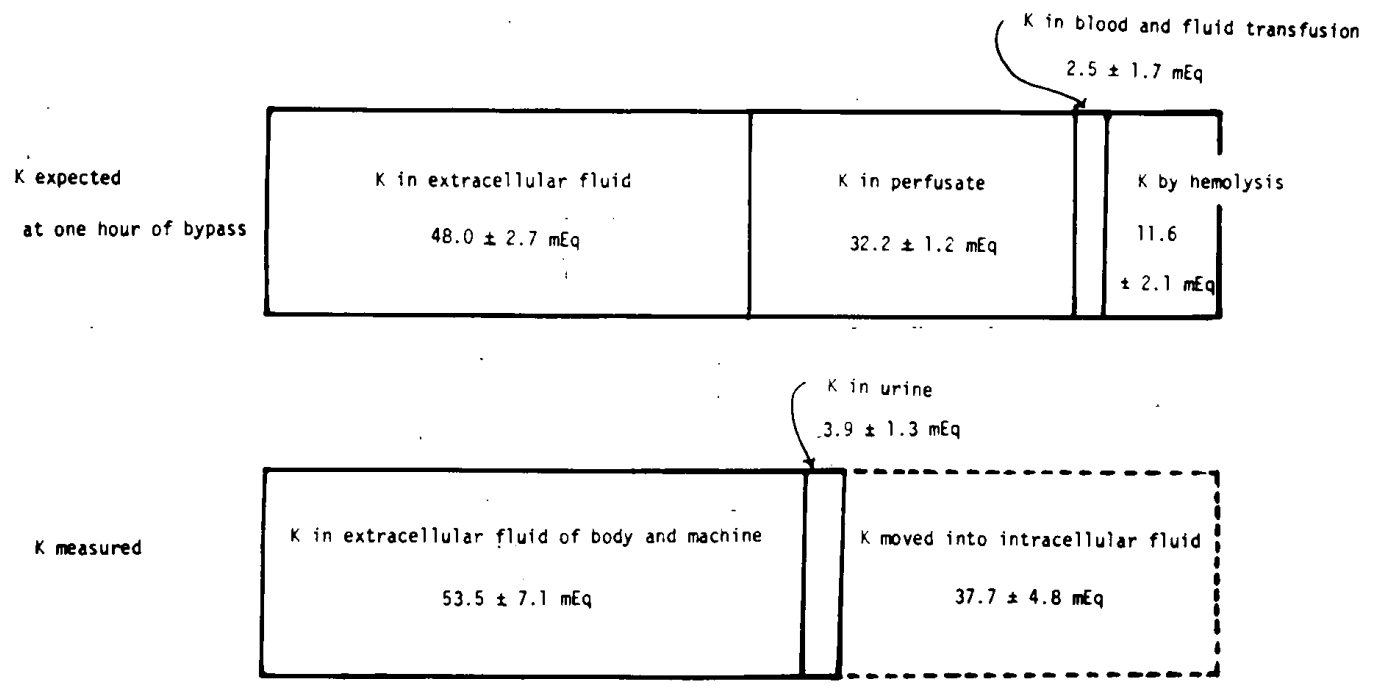

$(\bar{X} \pm$ SEM )

Fig.9. Balance study of potassium in extracellular fluid up to one hour after complete bypass.

ed into urine and the movement of potassium from extracellular fluid into the cells were conjectured in the above-mentioned two periods during which the potassium concentration of plasma falls off. In guessing the movement of potassium from the extracellular fluid into the cells, the amount of extracellular fluid of a body was hypothesized as $20 \%$ of body weight before extracorporeal circulation and $23 \%$ of body weight after the extracorporeal circulation, according to a report of Hiratsuka ${ }^{2}$ of this department. The amount of potassium supplemented by infusion and blood transfusion was calculated. By measuring hemolytic $\mathrm{Hb}$ during the extracorporeal circulation, the amount of potassium by hemolysis was calculated with the circulatory blood volume as $8 \%$ of body weight, with $\mathrm{Ht}$ as $45 \%$, and potassium concentration of red cell as $100 \mathrm{mEq} / \mathrm{L}$ : and this, too, was regarded as the amount of potassium supplemented.

By the calculation based on such an assumption, the amount of potassium escaped from the extracellular fluid into other than excretion into urine was hypothesized as having moved into the cells, and the amount thereof was calculated. The amount thus obtained is by no mean correct, for some hypothesis were built up during the course of calculation, and further, no consideration was given to the outflow of intracellular potassium due to the tissue disturbance following surgical operation. Nevertheless the authors thought it would denote a general trend of the movement of potassium in extracellular fluid.
The movement of potassium in extracellular fluid based on the calculation by such a hypothesis was calculated for two periods, namely, one up to one hour after complete bypass showing the first stage decrease of potassium and the other up to two hours after termination of the bypass showing the second stage decrease, the values of which were shown in Fig. 9 and Table I.

The amount of potassium excreted in to urine up to one hour after complete bypass stands at $3.9 \pm 1.3$ (SE) $\mathrm{mEq}$, and increased from the preoperative level. However, the amount of potassium supplemented by blood transfusion, infusion and hemolysis during that period is higher than that level, and on calculation, potassium of $37.7 \pm 4.8$ (SE) $\mathrm{mEq}$ is conjectured to have moved from extracellular fluid in to the cells (Fig. 9).

As to the movement of potassium in extracellular fluid up to two hours after termination of extracorporeal circulation, it varies with the serum potassium concentration; as to 6 cases in which serum potassium concentration is more than $4 \mathrm{mEq} / \mathrm{L}$ each, there occures the movement of potassium into the cells amounting to $15.2 \pm$ 2.4 (SE) $\mathrm{mEq}$ along with excretion of potassium $9.5 \pm 1.3$ (SE) $\mathrm{mEq}$ into urine. In 4 cases showing less than $4 \mathrm{mEq} / \mathrm{L}$, there is hardly any movement of potassium into the cells, and excretion into urine accounts for the most and there occurs the movement of potassium from inside the cells to extracellular fluid in some cases (Table I). 
TABLE I MOVEMENT OF POTASSIUM IN EXTRACELLULAR FLUID UP TO TWO HOURS AFTER TERMINATION OF BYPASS

\begin{tabular}{|c|c|c|}
\hline \multirow{2}{*}{$\begin{array}{l}\text { Plasma } K \text { at the end of bypass } \\
\qquad>4.0 \mathrm{mEq} / 1 \quad(n=6)\end{array}$} & $\begin{array}{l}K \text { moved into intracellular } \\
\text { fluid }\end{array}$ & $15.2 \pm 2.4 \mathrm{mEq}$ \\
\hline & $K$ excreted into urine & $9.5 \pm 1.3 \mathrm{mEq}$ \\
\hline \multirow{2}{*}{$\begin{array}{l}\text { Plasma } K \text { at the end of bypass } \\
\qquad 4.0 \mathrm{mEq} / 1 \quad(n=4)\end{array}$} & $\begin{array}{l}K \text { moved into intracellular } \\
\text { fluid }\end{array}$ & $1.2 \pm 2.3 \mathrm{mEq}$ \\
\hline & $K$ excreted into urine & $6.0 \pm 0.8 \mathrm{mEq}$ \\
\hline
\end{tabular}

$(\bar{X} \pm S E M)$

Regarding the movement of potassium from extracellular fluid into the cells, an influence of alkalosis was considered fomerly? However, on the acid-base equilibrium test of our cases, there was mild metabolic acidosis, although $\mathrm{pCO}_{2}$ fell of slightly, and $\mathrm{pH}$ was somewhat inclined to acidosis; therefore the influence of alkalosis was ruled out.

Accordingly, it is surmised that the movement of potassium in extracellular fluid into the cells in the first stage, that is one hour after the complete bypass, is influenced by hyperpotassemia, and that the movement of potassium in extracellular fluid into the cells in the second stage, that is after termination of the extracorporeal circulation, is due to potassium having moved into the cells along with the movement of glucose into the cells attendant on an increase in secretion of insulin?

The increase of blood sugar on the day of operation is due to sugar being produced by glycogenolysis and glucose of perfusate, for there is significant difference in blood sugar between the high blood sugar group and the normal blood sugar group of the perfusate during bypass and at one hour after bypass, but no statistical difference between the group of normal blood sugar perfusate and the group of closed heart operation. The blood insulin at one hour after bypass is high in the high blood sugar group, so it is inferred that the living body secretes more insulin to counteract that high blood sugar.

An increase in catecholamin by surgical invasion accelerates lipolysis and increases free fatty acids in blood? ${ }^{-9}$ But the difference in free fatty acid on the day of operation between the high blood sugar group and the normal blood sugar group for the perfusate indicated that the lipolysis is considered to be inhibited to some extent by high blood sugar and subsequent increase in insulin secretion.

The fluctuations in blood $\alpha$-amino acids indicate that proteolysis is inhibited temporarily by high blood sugar on the day of operation, and then protein catabolism and reproduction of sugar from amino acids are considered to be accelerated by the shortage of carbohydrate energy source.

From the results of these'tests, the high blood sugar perfuste tends to inhibit lipolysis and protein catabolism on the day of operation, and to shorten the catabolic phase after operation. Therefore, it is considered to exert beneficial action on the living body, if attention is paid to the fluctuations in the potassium balance.

In one patient who died of low output syndrome after corrective surgery of Fallot's tetralogy, the blood insulin was extremely low. There seemed to be a viscious circle where the circulatory insufficiecy resulted in a decrease of the insulin secretion and metabolic abnormality thereby deteriorates the function, and administration of glucose and insulin is considered to be indicated for such case.

\section{CONCLUSION}

(1) The blood insulin does not increase despite high blood sugar during the extracorporeal circulation, and it increases markedly after termination of the extracorporeal circulation, while the blood sugar level falls off.

(2) When the perfusate for the heart-lung machine is made to have high potassium concentration, the falling off of the plasma potassium concentration due to the extracorporeal circulation takes place up to one hour after the complete bypass and several hours after termination of the bypass. 
(3) Hypopotassemia is supposed to be caused by increased excretion of potassium into urine and the movement of potassium from extracellular fluid into the cells, and the falling off of plasma potassium concentration after the termination of the extracorporeal circulation is closely related to an increase in secretion of insulin.

(4) Comparison of the high blood sugar group and the normal blood sugar group of the perfusate for the heart-lung machine reveals that the former shows the higher blood sugar during the extracorporeal circulation and a conspicuous increase in secretion of insulin after the extracorporeal circulation.

(5) The high blood sugar group of the perfusate for the heart-lung machine showed a stronger tendency to inhibit lipolysis and protein catabolism on the day of operation and to shorten the catabolic phase after operation.

(6) In one patient who died of low output syndrome after the corrective surgery of Fallot's tetralogy, secretion of insulin fell off on the 3rd day after operation and thereafter. A vicious circle is thought of that circulatory insufficiency decreases secretion of insulin and metabolic abnormality caused therby deteriorates the cardiac function.

(7) In summary, high blood sugar perfusate for the heart-lung machine tends to inhibit lipolysis and protein catabolism on the day of operation and also to shorten the catabolic phase after operation; therefore, it is considered to exert beneficial action on the living body, if attention is paid to the fluctuation in the potassium balance.

\section{REFERENCES}

1. PORTE, D., Jr., GRABER, A. L., KAZUYA, T. \&
WILLIAMS, R. H.: The effect of epinephrine on immunoreactive insulin levels in man. $J$. Clinical Investigation, 45: 228, 1966.

2. HIRATSUKA, H.: Clinical studies of hypothermic perfusion with hemodilution technique, especially its influence on water and electroly tes changes, and renal function. Nagoya $J$. Medical Science, 31:51, 1968.

3. KRANSA, I. H., SHUSTER, M., BAENS, H., KREEL, I. and BARONOFSKY, I. D.: A study of acid-base and electrolyte derangrments after prolonged cardiopulmonary bypass. J. Thorac. \& Cardiovas. Surg., 42: 244, 1961.

4. KOGURE, H.: Studies on blood acid-base equilibrium by cardiac surgery using hypothermic perfusion with hemodilution. (in Japanese) J. Nagoya, Med. Ass., 91: 39, 1968.

5. ALLISON, S. P., PROWSE, K. \& CHAMBERLAIN, M, J.: Failure of insulin response to glucose load during operation and after myocardial infarction. Lanct, 1: 478, 1967.

6. MOFFITT, E. A., TARHAN, S., WHITE, R. D., MOLNAR, G. D. and Mc GOON, D. C.: Myocardial metabolism in open-heart surgery using whole blood in the pumpoxygenator. Mayo Clinic Proc., 46: 333, 1971.

7. YOSHITAKE, T., SAEGUSA, M., TSUNEMOTA, M., NOGUCHI, T., HIBI, I., ONO. Y., \& NIWA, M.: studies on the metadolism during open-heart surgery-metabolic influence of glucose, xylitol and Ringer-lactate solution. (in Japanese) Japanese J. Thoracic Surgery, 22: 499, 1969.

8. YOSHITAKE, T., SAEGUSA, M., TSUNEMOTỌ, M., \& NIWA, M.: Hypopotassemia folowing openheart surgery using extracoroporeal circulation. (in Japanese) Clinical Physiologey, $1: 182,1971$.

9. MOFFITT, E. A., ROSEVEAR, J. W., MOLNAR, G. D. \& McGOON, D. C.: Myocardial metaboliam in open-heart surgery. J. Thorac. \& Cardiovas. Surg., 59: 691, 1970 .

10. MAJID, P. A., GHOSH, P., PAKRASHI, B. C., INOSECU, M., DYKES, J. R. W. \& TAYLOR, S. H.: Insulin secretion after open-heart surgery with particular respact to pathogenesis of low cardiac output state. Brit. Heart J., 33: 6, 1971. 